\title{
The origin of anomalous diffusion in iron mononitride thin films
}

\author{
Akhil Tayal ${ }^{1}$, Mukul Gupta ${ }^{1 *}$ and Ajay Gupta ${ }^{2}$, P. R. Rajput ${ }^{3}$, J. Stahn ${ }^{4}$ \\ ${ }^{1}$ UGC-DAE Consortium for Scientific Research, University Campus, Khandwa Road, Indore 452 001, India \\ ${ }^{2}$ Amity Center for Spintronic Materials, Amity University, Sector 125, Noida-201 303, India \\ ${ }^{3}$ Atomic \& Molecular Physics Division, Bhabha Atomic Research Centre, Mumbai 400085, India and \\ ${ }^{4}$ Laboratory for Neutron Scattering and Imaging, \\ Paul Scherrer Institute, CH-5232 Villigen, Switzerland
}

(Dated: June 12, 2021)

\begin{abstract}
We have studied the origin of a counter intuitive diffusion behavior of $\mathrm{Fe}$ and $\mathrm{N}$ atoms in a iron mononitride (FeN) thin film. It was observed that in-spite of a larger atomic size, Fe tend to diffuse more rapidly than smaller $\mathrm{N}$ atoms. This only happens in the $\mathrm{N}$-rich region of Fe- $\mathrm{N}$ phase diagram, in the $\mathrm{N}$-poor regions, $\mathrm{N}$ diffusion coefficient is orders of magnitude larger than Fe. Detailed selfdiffusion measurements performed in FeN thin films reveal that the diffusion mechanism of Fe and $\mathrm{N}$ is different - Fe atoms diffuse through a complex process, which in addition to a volume diffusion, pre-dominantly controlled by a fast grain boundary diffusion. On the other hand $\mathrm{N}$ atoms diffuse through a classical volume-type diffusion process. Observed results have been explained in terms of stronger Fe-N (than Fe-Fe) bonds generally predicted theoretically for mononitride compositions of transition metals.
\end{abstract}

\section{INTRODUCTION}

Transition metal nitrides (TMN), specially $3 d$ TM mononitrides (TMMN) are an important class of materials exhibiting several interesting properties such as superhardness ${ }^{1-4}$, superconductivity ${ }^{5}$, corrosion and wear resistance $e^{6,7}$, etc. Along the $3 d$ series, there is a characteristic variation in the heat of formation $\left(\Delta H_{f}^{\circ}\right)$ for the $3 d$ TMMN - an initial increases to a maximum is followed by a decrease and a plateau in $\Delta H_{f}^{\circ} .{ }^{8}$ This inherently makes formation of early $3 d$ TMMN viz. ScN, TiN, VN, CrN easier than that of late ones viz. $\mathrm{MnN}$, FeN, CoN, NiN; e.g. $\Delta H_{f}^{\circ}=-338 \mathrm{kJmol}^{-1}$ for TiN and $-47 \mathrm{kJmol}^{-1}$ for $\mathrm{FeN}$ at $298 \mathrm{~K}$. As a result, mononitrides of $\mathrm{Ti}, \mathrm{V}, \mathrm{Cr}$ can be easily prepared and possess excellent thermal stability due to which they have been intensely investigated. ${ }^{9-13}$ On the other hand, magnetic mononitrides (e.g. MnN,FeN, $\mathrm{CoN}$ ) started to gain attention rather recently. ${ }^{14-21}$ Unlike early $3 d$ TMMN, FeN or $\mathrm{CoN}$ can only be formed in the form of thin films using non-equilibrium processes such as reactive sputtering $^{14,15,22,23}$, pulsed laser deposition ${ }^{24}$, and more recently by molecular beam epitaxy assisted with a rf-discharge nitrogen/ammonia source. ${ }^{19,25}$ Nickel mononitrides are yet to be evidenced experimentally. ${ }^{26,27}$ On the basis of energetics of mononitrides, FeN and $\mathrm{CoN}$ are expected to be metastable.

The metastable nature of FeN turned out to be a boon as FeN films were exploited as a source of spin-injection to semiconductors or diluted magnetic semiconductor in spintronics. ${ }^{28} \mathrm{FeN}$ when heated above $650 \mathrm{~K}$ yields a thermally stable $\gamma^{\prime}-\mathrm{Fe}_{4} \mathrm{~N}$ giving rise to an array of lithographically defined spin-valves. ${ }^{28}$ The mechanism leading to such structural transformation was assumed to be controlled by N-diffusion. XPS measurements for $\mathrm{Fe} 2 p$ and $\mathrm{N} 1 s$ peaks were used to measure $\mathrm{N}$ diffusion in $\mathrm{Fe} .{ }^{29}$ However, the conclusion drawn from such measurements that fast $\mathrm{N}$ diffusion leads to such transformations can be misleading since interdiffusion of $\mathrm{N}$ in $\mathrm{Fe}$, not selfdiffusion of $\mathrm{N}$ was measured.

Recent $\mathrm{Fe}$ and $\mathrm{N}$ self-diffusion measurements performed using neutron reflectivity (NR) show that N selfdiffusion is slower than Fe. ${ }^{15}$ This is a counter-intuitive result, defying established diffusion models for binary metal-metalloid systems where a smaller atom always diffuses faster than a larger atom. ${ }^{30}$ In absence of a suitable radioactive tracer, $\mathrm{N}$ self-diffusion is rather difficult to measure. ${ }^{9,31}$ Nevertheless by using ${ }^{15} \mathrm{~N}$ labelling, it can be obtained by doing depth-profile measurements using secondary ion mass spectroscopy (SIMS) ${ }^{32,33}$, nuclear reaction analysis (NRA) ${ }^{9}$ and NR. Among these, later provides an unique opportunity to measure selfdiffusion lengths down to $0.1 \mathrm{~nm}$ and a possibility to measure $\mathrm{N}$ self-diffusion in the low temperature regime (below $500 \mathrm{~K}) .{ }^{15,34}$

In the present work, we have carried out a study of $\mathrm{Fe}$ and $\mathrm{N}$ self-diffusion process to understand the origin of anomalous diffusion in non-magnetic FeN compound. Thin film samples were prepared using nitrogen alone as a sputtering gas in a reactive magnetron sputtering process. X-ray diffraction, absorption and Mössbauer spectroscopy measurements confirmed ZnS-type structure of samples. NR measurements show that $\mathrm{N}$ diffusion is slower than $\mathrm{Fe}$, however detailed diffusion mechanism was obtained from SIMS depth profiles using Le Claire's analysis $^{35,36}$ for grain-boundary $(g b)$ diffusion. It was found that in the low temperatures regime (up to $550 \mathrm{~K}$ ) fast Fe diffusion takes place predominantly through the $g b$ regions while $\mathrm{N}$ diffusion is a conventional volume type diffusion. As the temperature is increased beyond it, the difference between $\mathrm{Fe}$ and $\mathrm{N}$ diffusion decreases leading to structural transformations - essentially triggered by $\mathrm{Fe}$ diffusion and followed by $\mathrm{N}$ diffusion to the extent that $\mathrm{N}$ diffuses out of the system. This is an important result defying a general misconception the fast $\mathrm{N}$ diffusion leads to structural instability and can be applied to understand 
the thermal stability of transition metal mononitrides.

\section{EXPERIMENTAL}

In a direct current-magnetron sputtering (dc-MS) technique an iron target (purity 99.95\%) was sputtered using nitrogen (purity 99.9995\%) alone as the sputtering medium at a constant power of $100 \mathrm{~W} . \mathrm{N}_{2}$ gas was flown at a constant flow of $10 \mathrm{sccm}$ yielding a pressure of about $0.4 \mathrm{~Pa}$, while the pressure before gas flow was about $1 \times 10^{-5} \mathrm{~Pa}$. Fe target was pre-sputtered for 10 minutes using Ar gas to remove surface contaminations. Following samples were prepared at ambient temperature on $\mathrm{Si}(100)$ and float glass substrates:

(N1): $\left[\mathrm{FeN}(7.5 \mathrm{~nm}){ }^{57} \mathrm{FeN}(7.5 \mathrm{~nm})\right]_{\times 10}$

(N2): $\left[\mathrm{FeN}(7.5 \mathrm{~nm}) \mid \mathrm{Fe}^{15} \mathrm{~N}(7.5 \mathrm{~nm})\right]_{\times 10}$

(S): $\quad\left[\left.\mathrm{FeN}(100 \mathrm{~nm})\right|^{57} \mathrm{Fe}^{15} \mathrm{~N}(2 \mathrm{~nm}) \mid \mathrm{FeN}(100 \mathrm{~nm})\right]$

Samples (N1) and (N2) were used to measure Fe and N self-diffusion using NR, sample (S) was used to measure Fe and N self-diffusion simultaneously using SIMS. Natural Fe and ${ }^{57} \mathrm{Fe}(\sim 95 \%$ enriched) targets were sputtered using natural nitrogen and ${ }^{15} \mathrm{~N}(\sim 98 \%$ enriched) gases. To avoid any mixing of nitrogen isotope gases, chamber was evacuated after deposition of each layer and gas flows were monitored using a residual gas analyzer (RGA).

The long-range structure transformation in the samples were studied using x-ray diffraction (XRD) using a standard diffractometer (Bruker D8Advance) equipped with $\mathrm{Cu} \mathrm{K}-\alpha$ x-ray source and a silicon stripe detector (Lynxeye). The local structure was investigated using $\mathrm{x}$ ray absorption spectroscopy (XAS) and conversion electron Mössbauer spectroscopy (CEMS). The XAS measurements at $\mathrm{Fe}$ K-edge were performed at BL-9 beamline $^{37}$ and those at N K-edge at BL-1 beamline ${ }^{38}$, both at Indus-2 synchrotron radiation source at Indore. While Fe K-edge measurements were carried out in fluorescence mode, those at $\mathrm{N}$ K-edge were measured in total electron yield mode. To study the phase transformation, samples were annealed using a vacuum furnace for about two hours at each temperatures. NR measurements were performed at AMOR reflectometer at SINQ/PSI, Villigen, Switzerland. SIMS measurements were carried out on a Hiden Analytical SIMS Workstation using $\mathrm{O}_{2}^{+}$as primary with $5 \mathrm{keV}$ energy and $400 \mathrm{nA}$ beam current. The base pressure in SIMS measurement chamber was $1 \times 10^{-7} \mathrm{~Pa}$ and during measurement pressure was of the order of $1 \times 10^{-6} \mathrm{~Pa}$ due to differentially pumping of oxygen gas source.

\section{RESULTS AND DISCUSSION}

\section{A. Structural measurements}

Figure 1(a) shows XRD patterns of sample (N1) in the as-deposited state and after annealing at various temperatures. In the as-deposited state, a single broad peak
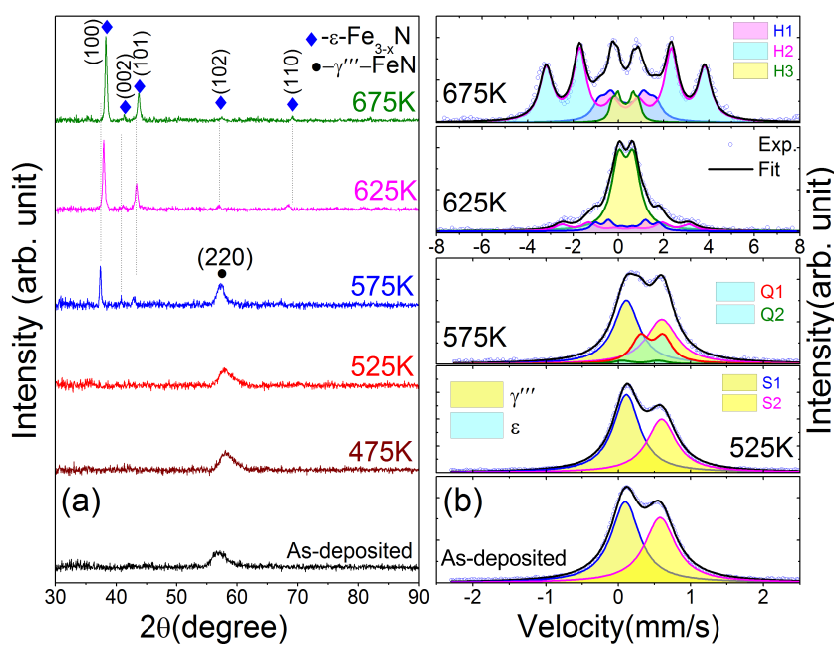

FIG. 1. XRD(a) and CEMS(b) patterns of sample (N1) in the as-deposited state and after annealing at different temperatures.

appears around $2 \theta=56$ degree. From CEMS and XAS measurements (shown later), it was confirmed that the formed phase is $\gamma^{\prime \prime \prime}$-FeN having ZnS-type structure oriented along (220) plane. ${ }^{14,17}$ After annealing at $475 \mathrm{~K}$, a shift in the peak position towards higher angle was observed. However, the XRD pattern of sample annealed at $525 \mathrm{~K}$ is almost identical to that of previously annealed sample. Such shift in the peak position is an indication of annihilation of free volume leading to densification of the structure. ${ }^{39,40}$ It is interesting to note that the average crystallite size $\left(g_{s}\right)$ (calculated using Scherrer formula ${ }^{41}$ ) remains at a value of about $\sim 5 \mathrm{~nm}$ upto an annealing temperature of $525 \mathrm{~K}$. At a higher temperature of $575 \mathrm{~K}$, additional peaks corresponding to $\varepsilon-\mathrm{Fe}_{3-\mathrm{z}} \mathrm{N}(0 \leq \mathrm{z} \leq 1)$ start to appear. With further increasing annealing temperatures, growth of $\varepsilon-\mathrm{Fe}_{3-\mathrm{z}} \mathrm{N}$ phase can be seen. Along with it a continuous shift of peaks position towards higher $2 \theta$ values were observed indicating ' $z \rightarrow 0$ '.

Figure 1(b) shows CEMS spectra for sample (N1) in the as-deposited state and after annealing. Obtained CEMS spectra were fitted using a computer program NORMOS/SITE ${ }^{42}$ and fitted parameters are given in table I. As-deposited and the sample annealed at $525 \mathrm{~K}$ shows an asymmetric doublet which is typically observed for $\gamma^{\prime \prime \prime}-\mathrm{FeN}$ in ZnS-type structure. Such spectra can be de-convoluted into two singlets: one with a smaller and other with a larger value of isomer shift $(\delta)$. The singlet with $\delta=0.01 \mathrm{~mm} / \mathrm{s}$ corresponds to Fe surrounded tetrahedrally to $\mathrm{N}$, while other singlet originates due to defects and vacancies. ${ }^{14,17,43}$ Annealing above $575 \mathrm{~K}$ results in appreciable changes in CEMS spectrum, at this temperature it can be best fitted using mixture of two singlets and two quadrupole split doublets corresponding to $\gamma^{\prime \prime \prime}$ and $\varepsilon-\mathrm{Fe}_{3-z} \mathrm{~N}$ phase, respectively. Obtained fitting parameters match-well with the reported values. ${ }^{22,43} \mathrm{It}$ is known that $\varepsilon-\mathrm{Fe}_{3-\mathrm{z}} \mathrm{N}$ phase exist in a wide composi- 
TABLE I. Conversion electron Mössbauer spectroscopy (CEMS) parameters for iron mononitride thin films in the as-deposited state $(300 \mathrm{~K})$ and after annealing at various temperatures. Here $\mathrm{S}$ stands for a singlet, $\mathrm{Q}$ for a doublet and $\mathrm{H}$ for a sextet, $\delta$ for isomer shift, $\Gamma$ for quadrupole splitting, $\mathbf{H}$ for hyperfine field and RA for relative area.

\begin{tabular}{|c|c|c|c|c|c|}
\hline $\begin{array}{c}\mathrm{T} \\
(\mathrm{K})\end{array}$ & Component & $\begin{array}{l}\mathrm{t} \quad \delta \\
(\mathrm{mm} / \mathrm{s}) \\
\pm 0.03\end{array}$ & $\begin{array}{c}\Gamma \\
(\mathrm{mm} / \mathrm{s}) \\
\pm 0.03\end{array}$ & $\begin{array}{c}\mathbf{H} \\
(\text { Tesla }) \\
\pm 0.2\end{array}$ & $\begin{array}{l}\overline{\mathrm{RA}} \\
(\%) \\
\pm 2\end{array}$ \\
\hline \multirow[t]{2}{*}{300} & S1 & 0.10 & - & - & 54 \\
\hline & S2 & 0.57 & - & - & 46 \\
\hline \multirow[t]{2}{*}{525} & S1 & 0.11 & - & - & 57 \\
\hline & $\mathrm{S} 2$ & 0.60 & - & - & 43 \\
\hline \multirow[t]{4}{*}{575} & $\overline{\mathrm{S} 1}$ & 0.11 & - & - & 40 \\
\hline & S2 & 0.60 & - & - & 34 \\
\hline & Q1 & 0.46 & 0.31 & - & 23 \\
\hline & Q2 & 0.30 & 0.50 & - & 3 \\
\hline \multirow[t]{3}{*}{625} & H1 & 0.38 & 0.0 & 8.7 & 13 \\
\hline & $\mathrm{H} 2$ & 0.31 & 0.0 & 17.4 & 17 \\
\hline & H3 & 0.33 & 0.65 & - & 70 \\
\hline \multirow[t]{3}{*}{675} & $\overline{\mathrm{H} 1}$ & 0.40 & 0.0 & 7.6 & 22 \\
\hline & $\mathrm{H} 2$ & 0.31 & 0.0 & 21.7 & 68 \\
\hline & H3 & 0.30 & 0.0 & 3.6 & 10 \\
\hline
\end{tabular}

tion range in which its magnetic properties also get tuned with nitrogen concentration. ${ }^{44}$ It was observed that, at room temperature, as ' $z \rightarrow 1$ ' $\varepsilon-\mathrm{Fe}_{3-\mathrm{z}} \mathrm{N}$ phase becomes non-magnetic, whereas as ' $z \rightarrow 0$ ' it becomes ferromagnetic. Appearance of sextet confirms ferromagnetic ordering which is also supported by XRD results indicating ' $z \rightarrow 0$ ' in $\varepsilon-\mathrm{Fe}_{3-\mathrm{z}} \mathrm{N}$. Obtained fitting parameters (table I) for CEMS spectra measured above $575 \mathrm{~K}$ matchwell with the reported values. ${ }^{44}$

To get precise information about the local structure of $\mathrm{Fe}$ and N, XAS measurements at Fe and N K-edge were performed on sample (N1) and are shown in figure 2 . A strong pre-edge peak around $7113 \mathrm{eV}$ can be seen before Fe K-edge. This is a signature of quadrupole transition and its probability strongly depends on the direction of the local electric field, which in turns gets influenced by local site symmetry. ${ }^{45}$ For such a pre-edge peak to appear, inversion symmetry must be broken (transition from a bound core level to a higher level empty state). This is only possible when Fe is surrounded tetrahedrally to $\mathrm{N}$ atoms because this arrangement is asymmetric under inversion. ${ }^{45}$ This clearly indicates ZnS-type structure (tetrahedral coordination of $\mathrm{Fe}$ atoms) in our samples. Such pre-edge feature has been frequently used to assign tetrahedral or octahedral coordination in transition metal complexes such as $\mathrm{Mn}^{46}, \mathrm{Cr}^{47}$, etc. To further confirm this result, XAS spectra was also taken at N K-edge (shown in the inset of figure 2). Apart from edge feature ' $a$ ' at $401 \mathrm{eV}$, three features that are assigned as $(c, d$ and $e$ ), are observed due to the electronic transition to empty N-2p state hybridized to Fe-3d state. ${ }^{17}$ Various TMMN (viz. $\mathrm{Ti}, \mathrm{Cr}, \mathrm{V}$ ) having $\mathrm{NaCl}$ type structure, the feature ' $a$ ' splits into two components due to crystal field split-

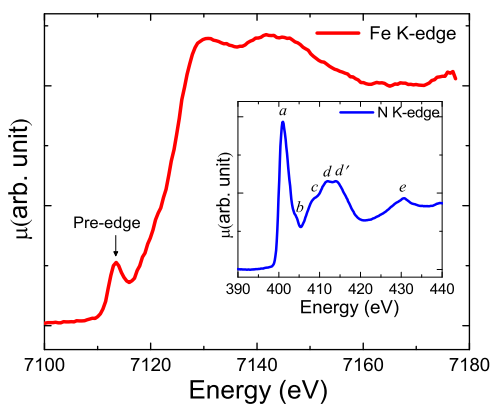

FIG. 2. Fe K-edge XAS spectra of iron mononitride thin films. Inset of the figure shows spectra taken at $\mathrm{N} \mathrm{K}$-edge.

ting caused by the octahedral coordination of $\mathrm{N}$ atoms surrounding the metal ions. ${ }^{48,49}$ Absence of any splitting around the feature ' $a$ ' is a clear indication of tetrahedral coordination of Fe surrounding $\mathrm{N}$ atoms. Less intense features $(b)$ and $\left(d^{\prime}\right)$ observed in the spectra are due to surface oxidation state. ${ }^{17}$ Combining the information obtained from XAS measurements, it can be confirmed that $\mathrm{FeN}$ phase has a ZnS-type structure. This is also in agreement with low temperature high field Mössbauer spectroscopy measurements in this compound. ${ }^{14}$

\section{B. Self-diffusion measurements}

NR is a precise tool to measure atomic self-diffusion and diffusivity as low as $1 \times 10^{-25} \mathrm{~m}^{2} \mathrm{~s}^{-1}$ have been measured using this technique. ${ }^{32,34,50-52}$ It is known that neutron scattering length $\left(b_{n}\right)$ varies for isotopes for ${ }^{\text {natural }} \mathrm{Fe},{ }^{57} \mathrm{Fe}$, ${ }^{\text {natural } \mathrm{N}}$, and ${ }^{15} \mathrm{~N} b_{n}=9.45 \mathrm{fm}, 2.3 \mathrm{fm}$, $9.36 \mathrm{fm}$ and $6.6 \mathrm{fm}$, respectively. Therefore, periodic isotope multilayer are widely used to study atomic selfdiffusion using NR. ${ }^{15,32,34,50-52}$ Figure 3 (a) and (b) shows NR patterns for samples (N1) and (N2), respectively. Bragg peaks appearing due to isotopic contrast of ${ }^{n a t} \mathrm{Fe} /{ }^{57} \mathrm{Fe}$ and ${ }^{\text {nat }} \mathrm{N} /{ }^{15} \mathrm{~N}$ can be seen clearly. Patterns were fitted using a computer program based on Parratt formulism ${ }^{53,54}$ and obtained layer thickness for sample $(\mathrm{N} 1)$ is $7.9 \mathrm{~nm},(\mathrm{~N} 2)$ is $7.3 \mathrm{~nm}$, close to nominal values.

After annealing the intensity of Bragg peak start to decay and such decay is more rapid for sample (N1) than for (N2). A decay of Bragg peak intensity is a measure of atomic diffusion across interfaces. Obtained results clearly indicate that Fe self-diffusion is faster than N. Detailed fitting of NR data yields diffusion length $\left(\mathrm{L}_{\mathrm{d}}\right)$, which are plotted in the inset of figure $3(\mathrm{~b})$. Clearly, $\mathrm{L}_{\mathrm{d}}$ is significantly larger for Fe than for N. This result, although counter intuitive, agrees well with previous studies on $\gamma^{\prime \prime \prime}$-FeN compound. ${ }^{15}$ To get further insight leading to such anomalous behavior, we did detailed SIMS measurements on sample (S). With SIMS, unlike NR, both Fe and N self-diffusion can be measured simultaneously.

Figure 4 shows SIMS depth-profile in sample (S) for ${ }^{57} \mathrm{Fe}(\mathrm{a})$ and ${ }^{15} \mathrm{~N}(\mathrm{~b})$, isochronally annealed for $1 \mathrm{hr}$ at each temperature. As annealing temperature is increased, the 


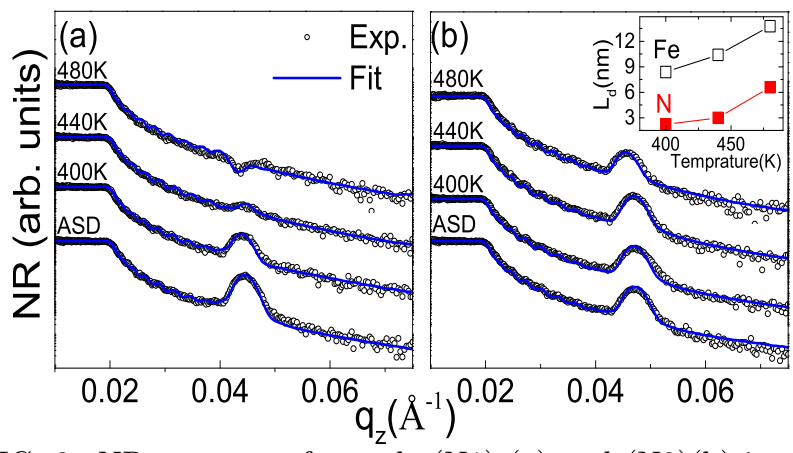

FIG. 3. NR patterns of sample (N1) (a) and (N2)(b) in the as-deposited state (ASD) and after annealing at different temperatures for 2 hours. Here scatter points are experimental data and solid line is fit to them. Inset of figure(b) shows variation of diffusion length $\left(\mathrm{L}_{\mathrm{d}}\right)$ obtained by fitting. Here solid and open symbols represent for Fe and $\mathrm{N}$ diffusion, respectively. Typical error bars in calculating $\mathrm{L}_{\mathrm{d}}$ are less than size of symbols.

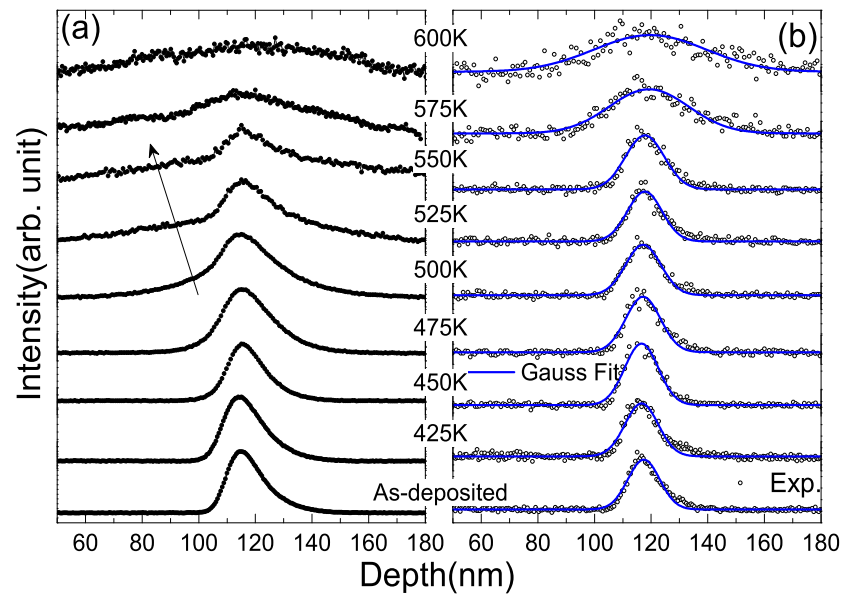

FIG. 4. SIMS depth profile of ${ }^{57} \mathrm{Fe}(\mathrm{a})$ and ${ }^{15} \mathrm{~N}(\mathrm{~b})$ for sample (S) after annealing at different temperatures.
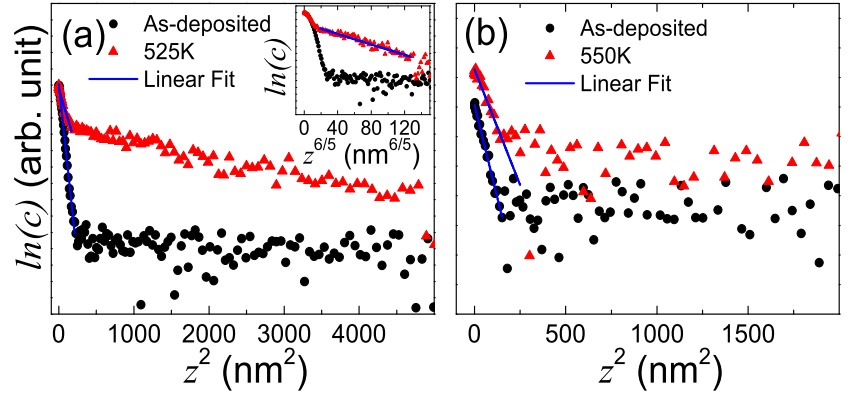

FIG. 5. SIMS depth-profile for sample (S) showing ${ }^{57} \mathrm{Fe}(\mathrm{a})$ and ${ }^{15} \mathrm{~N}(\mathrm{~b})$ distribution plotted versus $z^{2}$ to calculate volume diffusion, in the as-deposited and annealed state. Inset of (a) shows depth-profile of ${ }^{57} \mathrm{Fe}$ plotted versus $z^{6 / 5}$ to calculate grain-boundary diffusion. width of ${ }^{57} \mathrm{Fe}$ profiles become broader than those of ${ }^{15} \mathrm{~N}$, indicating faster $\mathrm{Fe}$ self-diffusion than $\mathrm{N}$, in agreement with NR results. For such SIMS depth-profiles, concentration profile of an element at a depth $z$ can be fitted using a Gaussian distribution function to obtain volume diffusivity $\left(D_{V}\right)$ using $^{55}$ :

$$
c(z, t)=\frac{\text { const. }}{\sqrt{\pi D_{V} t}} \exp \left(\frac{-z^{2}}{4 D_{V} t}\right)
$$

Here $t$ is annealing time at a temperature $T$. Alternatively, a linear relation between $\ln (c)$ and $z^{2}$, yields slope of the fitted line, given by: slope $=-1 / 4 D_{V} t$. Obtained $\mathrm{N}$ diffusivities are shown in $6(\mathrm{c})$. While ${ }^{15} \mathrm{~N}$ profiles fits well to this equation, ${ }^{57} \mathrm{Fe}$ profiles cannot be fitted using equation 1 alone, specially above $475 \mathrm{~K}$. As shown more clearly in figure $5,{ }^{15} \mathrm{~N}$ profiles have single slope, ${ }^{57} \mathrm{Fe}$ profiles have two distinct slopes. Fe diffusivity upto $475 \mathrm{~K}$ can be obtained using equation 1 , above it, the additional slope can be fitted using Le Claire's analysis ${ }^{35}$ for $g b$ diffusion. An skewness in ${ }^{57} \mathrm{Fe}$ depth-profiles above $475 \mathrm{~K}$ (marked by an arrow in figure $4(\mathrm{a})$ ) is an indication of competing diffusion processes taking place through grainboundaries in addition to a volume type diffusion. ${ }^{36,56}$ Since $D_{g b}>>D_{V}$, it can be assumed that fast Fe diffusion observed in our samples is primarily $g b$ diffusion. In this case, $D_{g b}$ can be obtained from the slope of 'Inc' versus ' $z^{6 / 5}$ ' curve, using Suzuoka's instantaneous-source solution equation 36,57 :

$$
s \delta D_{g b}=1.084\left(\frac{D_{V}^{0.91}}{t^{1.03}}\right)^{1 / 1.94}\left(-\frac{\partial \ln c}{\partial z^{6 / 5}}\right)^{-5 / 2.91}
$$

Here, $s$ is segregation factor, $\delta$ is width of $g b$. As such experimental estimation of $\delta$ is difficult, a good approximation is $\delta \sim 0.5 \mathrm{~nm}$, as often found in literature. ${ }^{58} \mathrm{Eq} .2$ is applicable for the condition in which a dimensionless quantity $\beta=\frac{s \delta D_{g b}}{2 D_{V}^{3 / 2} t^{1 / 2}}$, has values between 10 and 100 . Since in our case we find $\beta \sim 23$ at $500 \mathrm{~K}$, equation 2 can be applied to calculate $s D_{g b}$. Inset of the figure $5(\mathrm{a})$ shows a linear fit to a curve plotted between ' $\ln c$ ' and $z^{6 / 5}$, after annealing at $525 \mathrm{~K}$. Similar analysis was carried out at other annealing temperatures and obtained values of $s D_{g b}$ and $D_{V}$ are shown figure $6(\mathrm{a})$ and (b), respectively.

Grain-boundary diffusion is a complex process in which several competing processes may take place simultaneously. ${ }^{56}$ However for a given temperature range and duration, only few of them may get activated. Thus different kinetic regimes of $D_{g b}$ have been observed, ascribed by Harrison. ${ }^{36,59}$ According to this classification, $D_{g b}$ has three regimes known as type- $\mathrm{A}, \mathrm{B}$, and $\mathrm{C}$. These regimes can be differentiated according to a relation between $g b$ penetration depth $\left(L_{g b}=\sqrt{\left(D_{g b} t\right)}\right)$, volume penetration depth $\left(L_{V}=\sqrt{\left(D_{V} t\right)}\right)$ and grain size $\left(g_{s}\right) .{ }^{60}$ For type-C regime $L_{g b}<g_{s}$, for type-B regime $L_{V}<g_{s}$, and for type-A regime $L_{V}>g_{s}{ }^{60}$. Using these inequalities, obtained values $D_{V}$ and $D_{g b}$ can be divided into distinct 


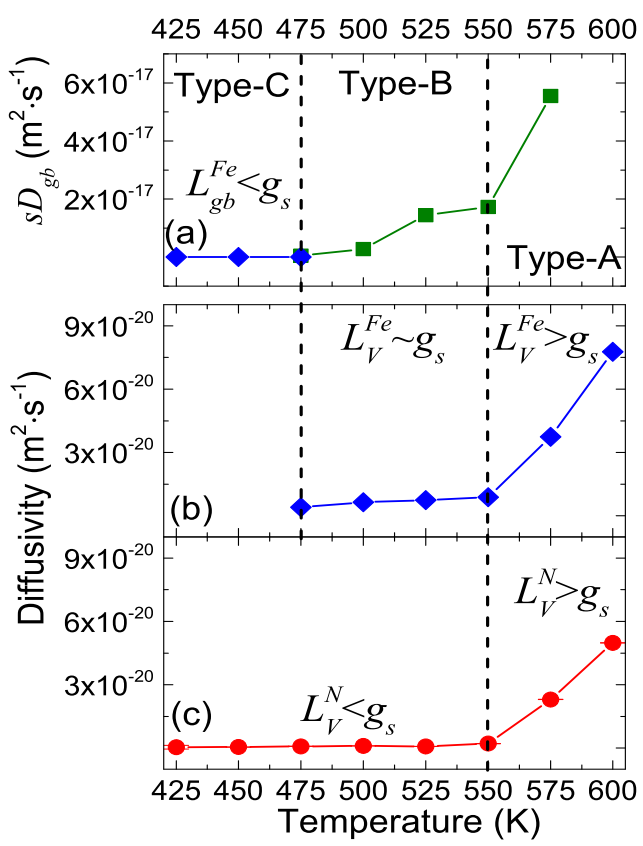

FIG. 6. Variation of $D_{g b}$ of $\mathrm{Fe}(\mathrm{a}), D_{V}$ of $\mathrm{Fe}(\mathrm{b})$ and $D_{V}$ of $\mathrm{N}(\mathrm{c})$ at different annealing temperatures. Typical error bars in estimation of diffusivity are of the order of size of symbols.

kinetic regimes as shown in figure 6 . We find that for $\mathrm{Fe}$ diffusion, $L_{g b}<g_{s}\left(L_{g b} \sim 2 \mathrm{~nm}, g_{s} \sim 5 \mathrm{~nm}\right)$ for $\mathrm{T}<475 \mathrm{~K}$; for $475 \mathrm{~K}<\mathrm{T}<550 \mathrm{~K}, L_{V} \sim g_{s}$ and $L_{V}>g_{s}$ for $\mathrm{T}>550 \mathrm{~K}$ corresponding to type-C, B and A kinetics, respectively.

On the other hand for $\mathrm{N}$ diffusion, we find $L_{V}<g_{s}$ below $550 \mathrm{~K}$ and above it $L_{V}>g_{s}$. This indicates $\mathrm{N}$ diffusion is taking place within a grain below $550 \mathrm{~K}$ and as temperature is raised beyond it, multi-grain $\mathrm{N}$ diffusion takes over. It appears that $\mathrm{Fe}$ and $\mathrm{N}$ diffusion mechanism is significantly different. While only $D_{V}$ takes place for $\mathrm{N}, \mathrm{Fe}$ diffusion process seems to be more complex having distinct kinetic regimes $\mathrm{C}, \mathrm{B}$ and $\mathrm{A}$ as annealing temperature increases. It is known that in type$\mathrm{C}$ regime, diffusion takes place pre-dominantly through grain-boundaries leading to segregating of $\mathrm{Fe}$ atoms in the $g b$ region. In type-B regime, in addition to $g b$ diffusion, $D_{V}$ starts. Though it is not too effective to cause any structural or magnetic transformation in this case. Finally above $550 \mathrm{~K}, D_{V}$ of both Fe and $\mathrm{N}$ becomes comparable. Observed diffusion behavior gives a direct correlation between Fe and N self-diffusion with phase transformation. This is contrary to general preassumption that only $\mathrm{N}$ diffusion leads to phase transformation.

Since isochronal diffusion measurements only give a snap shot of diffusion process, more insight about involved diffusion mechanism was obtained by doing detailed isothermal diffusion measurements between 475$550 \mathrm{~K}$ (for $\mathrm{Fe}$ ) and $525-600 \mathrm{~K}$ (for $\mathrm{N}$ ) in the steps of $25 \mathrm{~K}$ for different annealing times. Representative SIMS depth-profiles taken at $525 \mathrm{~K}$ after various annealing times are shown in figure 7 for Fe (a) and N (b). Fol-
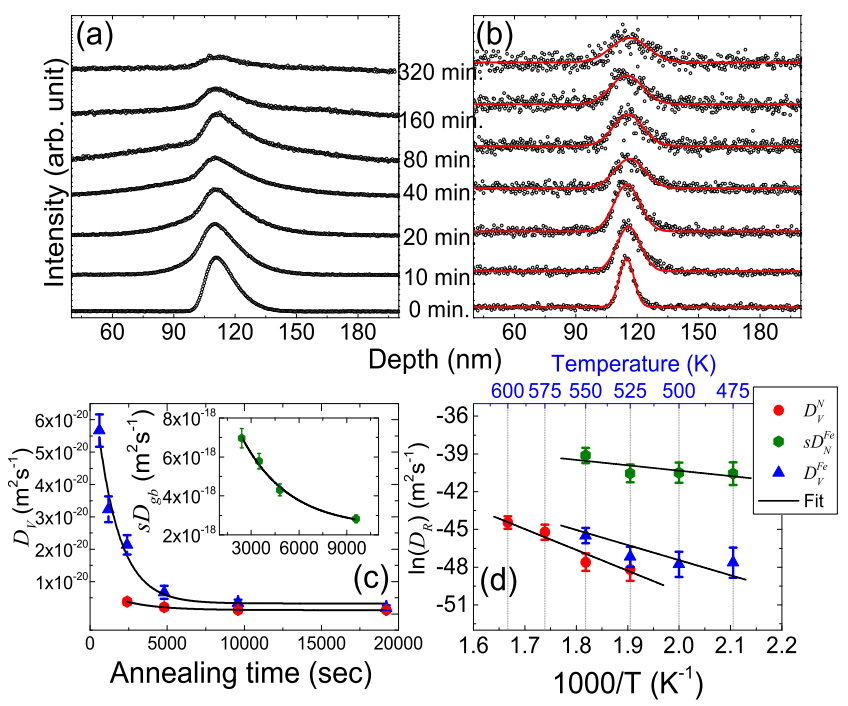

FIG. 7. SIMS depth-profile of ${ }^{57} \mathrm{Fe}(\mathrm{a})$ and ${ }^{15} \mathrm{~N}(\mathrm{~b})$ for sample (S) annealed at $525 \mathrm{~K}$ for different annealing times. Obtained values of $D_{V}$ for $\mathrm{Fe}$ and $\mathrm{N}$ annealed for different times at $525 \mathrm{~K}$ (c). Inset of figure (c) shows variation in $D_{g b}$ of Fe. Arrhenius behavior of volume and grain-boundary diffusion of Fe and $\mathrm{N}(\mathrm{d})$.

lowing a similar process $\mathrm{D}_{V}$ and $\mathrm{D}_{g b}$ was calculated and shown in figure $7(\mathrm{c})$. Time-dependent diffusivity data can be fitted using:

$$
D=D_{R}+A \cdot \exp (-t / \tau)
$$

Where, $D_{R}$ is diffusivity in relaxed state, $A$ a constant, $t$ annealing time, and $\tau$ is relaxation time. Using 3 we get $\tau=1445( \pm 300) \mathrm{s}$, and $2192( \pm 300) \mathrm{s}$, respectively for Fe and $\mathrm{N} D_{V}$; while for Fe $\mathrm{D}_{g b}, \tau=2986( \pm 300)$ s. Much longer values of $\tau$ for $g b$ diffusion indicate that it remain active for a longer time due to availability of large volume of $g b$. Obtained values of $D_{R}$ follows Arrhenius behavior given by:

$$
D_{R}=D_{0} \exp \left(-E / k_{\mathrm{B}} T\right)
$$

Here, $D_{0}$ denotes pre-exponential factor, $E$ activation energy, $T$ temperature and $k_{\mathrm{B}}$ Boltzmann's constant. The obtained values of $E$ for $D_{V}$ of $\mathrm{Fe}$ and $\mathrm{N}$ are $1.0 \pm 0.2 \mathrm{eV}$ and $1.4 \pm 0.2 \mathrm{eV}$, respectively while for $\mathrm{Fe}$ $D_{g b}$ it is $0.6 \pm 0.2 \mathrm{eV}$. As expected, smaller value of $E$ for the $g b$ diffusion signifies that it starts at a relatively lower temperature as compared to $D_{V}$. Interestingly, we observe a slightly higher value of the activation energy for $D_{V}$ of $\mathrm{N}$ as compared to Fe (also $\tau$ for $\mathrm{N} D_{V}$ was larger than $\mathrm{Fe}$ ). Observed discrepancy within $D_{V}$ of $\mathrm{Fe}$ and $\mathrm{N}$ can be understood due to a stronger metalnitrogen (than metal-metal) interaction predicted theoretically for $\mathrm{TMMN}^{8,61}$. Unlike oxides, TMN are stabilized by a dominant metal-metal interaction and there- 
fore metal-metal bonds are stronger. However mononitride having ZnS-type or NaCl-type structure, a volume expansion of $f c c$ lattice takes place to accommodate $\mathrm{N}$ atoms in the interstitial positions. Early theoretical calculations predicted that the interaction distances are larger and bond energies are significantly smaller for metal-metal bonds as compared to metal-nitrogen bonds for $3 d$ TMMN. ${ }^{62}$ More recent band structure calculations based of density-functional theory, observed localization of metal valance bonds leading to weakened metal-metal bonding in mononitrides. ${ }^{61}$ In additions a suppression in $\mathrm{N}$ migration vacancy was predicted for slightly offstoichiometry mononitrides of various TMN. ${ }^{12,13}$ From these theoretical studies it can be inferred that metalmetal bonds are readily broken. This situation may lead to segregation of $\mathrm{Fe}$ atoms in the $g b$ region, leading to faster Fe diffusion as compared to $\mathrm{N}$ diffusion, under identical thermodynamic conditions.

\section{CONCLUSION}

Iron mononitride thin films studied in this work, show an anomalous self-diffusion behavior in which $\mathrm{N}$ atoms tend to diffuse slower than Fe atoms. SIMS depth-profile measurements reveal that the diffusion mechanism for $\mathrm{Fe}$ and $\mathrm{N}$ is different. While $\mathrm{N}$ diffuses only via a volumetype diffusion process, $\mathrm{Fe}$ in addition to volume, predominantly diffuses through grain-boundaries. Fe grainboundary diffusion was about two orders of magnitude more than its volume diffusion. Even for volume diffusion, $\mathrm{N}$ diffusion was found to be less than Fe. This can be understood in terms of stronger metal-nitrogen bonds (than metal-metal) predicted theoretically for transition metal mononitrides, evidenced experimentally in this work.

\section{ACKNOWLEDGMENTS}

A part of this work was performed at AMOR, Swiss Spallation Neutron Source, Paul Scherrer Institute, Villigen, Switzerland. We acknowledge D. M. Phase, D. K. Shukla, R. Sah and S. Karwal for utilization of BL1 beamline and S. N. Jha, D. Bhattachrya for BL9 beamline. We are thankful to V.R. Reddy and A. Gome for CEMS measurements; M. Horisberger for sample preparation; L. Behra for XRD and SIMS measurements. We are thankful to A. K. Sinha and V. Ganesan for support and encouragement. A.T. is thankful to CSIR India for a research fellowship. *mgupta@csr.res.in/dr.mukul.gupta@gmail.com

1 S. Vepřek, Journal of Vacuum Science and Technology A 17 (1999)

2 S.-H. Jhi, S. G. Louie, M. L. Cohen, and J. Ihm, Phys. Rev. Lett. 86, 3348 (Apr 2001), http://link.aps.org/ doi/10.1103/PhysRevLett.86.3348

3 S.-H. Jhi, J. Ihm, S. G. Louie, and M. L. Cohen, Nature 399, 132 (1999)

4 S. Hao, B. Delley, S. Veprek, and C. Stampfl, Phys. Rev. Lett. 97, 086102 (Aug 2006), http://link.aps.org/doi/ 10.1103/PhysRevLett. 97.086102

5 S. Yamanaka, K.-i. Hotehama, and H. Kawaji, Nature 392, $580(1998)$

${ }^{6}$ P. Steneteg, O. Hellman, O. Y. Vekilova, N. Shulumba, F. Tasnádi, and I. A. Abrikosov, Phys. Rev. B 87, 094114 (Mar 2013), http://link.aps.org/doi/10.1103/ PhysRevB.87.094114

7 W. D. Sproul, Science 273, 889 (1996), http://www.sciencemag.org/content/273/5277/889.full.pdf, http://www. sciencemag. org/content/273/5277/889. abstract

8 J. Häglund, A. Fernández Guillermet, G. Grimvall, and M. Körling, Phys. Rev. B 48, 11685 (Oct 1993), http: //link.aps.org/doi/10.1103/PhysRevB.48.11685

9 L. Hultman, Vacuum 57, 1 (2000), ISSN 0042-207X, http://www.sciencedirect.com/science/article/pii/ S0042207X00001433

10 S. Zhang, D. Sun, Y. Fu, and H. Du, Surface and Coatings Technology 167, 113 (2003), ISSN 02578972, proceedings of the Symposium on Technological Advances and Performance of Engineering Thin Films and Surface Coatings at the 1st International Conference on Materials Processing for Properties and Performance (MP3), http://www. sciencedirect.com/science/ article/pii/S0257897202009039

11 I. Milošev, H.-H. Strehblow, and B. Navinšek, Thin Solid Films 303, 246 (1997), ISSN 0040-6090, http://www.sciencedirect.com/science/article/ $\mathrm{pii} / \mathrm{S} 0040609097000692$

12 L. Tsetseris, N. Kalfagiannis, S. Logothetidis, and S. T. Pantelides, Phys. Rev. B 76, 224107 (Dec 2007), http: //link.aps.org/doi/10.1103/PhysRevB.76.224107

13 L. Tsetseris, N. Kalfagiannis, S. Logothetidis, and S. T. Pantelides, Phys. Rev. Lett. 99, 125503 (Sep 2007), http: //link.aps.org/doi/10.1103/PhysRevLett.99.125503

14 M. Gupta, A. Tayal, A. Gupta, V. Reddy, M. Horisberger, and J. Stahn, J. Alloys and Compounds 509, 8283 (2011), ISSN 0925-8388, http://www.sciencedirect. com/science/article/pii/S0925838811010206

15 M. Gupta, A. Tayal, A. Gupta, R. Gupta, J. Stahn, M. Horisberger, and A. Wildes, J. Appl. Phys. 110, 123518 (2011)

16 A. Houari, S. F. Matar, M. A. Belkhir, and M. Nakhl, Phys. Rev. B 75, 064420 (Feb 2007), http://link.aps. org/doi/10.1103/PhysRevB.75.064420

17 I. Jouanny, P. Weisbecker, V. Demange, M. Grafouté, O. Peña, and E. Bauer-Grosse, Thin Solid Films 518, 1883 (2010)

18 X. Liu, H. Lu, M. He, K. Jin, G. Yang, H. Ni, and K. Zhao, Journal of Alloys and Compounds 582, 75 (2014), ISSN 0925-8388, http://www.sciencedirect. com/science/article/pii/S092583881301846X 
19 C. Navío, J. Alvarez, M. J. Capitan, F. Yndurain, and R. Miranda, Phys. Rev. B 78, 155417 (2008)

${ }^{20} \mathrm{X}$. Wang, H. Jia, W. Zheng, Y. Chen, and S. Feng, Thin Solid Films 517, 4419 (2009), ISSN 0040-6090, http://www.sciencedirect.com/science/article/pii/ S0040609009006695

21 S. Bhattacharyya, The Journal of Physical Chemistry C 119, 1601 (2015), http://dx.doi.org/10.1021/jp510606z, http://dx.doi.org/10.1021/jp510606z

22 P. Schaaf, Prog. Mater. Sci. 47, 1 (2002)

23 J.-S. Fang, L.-C. Yang, C.-S. Hsu, G.-S. Chen, Y.-W. Lin, and G.-S. Chen, Journal of Vacuum Science \& Technology A 22 (2004)

24 M. Gupta, A. Gupta, P. Bhattacharya, P. Misra, and L. Kukreja, J. Alloys and Compounds 326, 265 (2001), http://www.sciencedirect.com/science/ article/pii/S0925838801013160

25 M. Naito, K. Uehara, R. Takeda, Y. Taniyasu, and H. Yamamoto, Journal of Crystal Growth 415, 36 (2015), ISSN 0022-0248, http://www.sciencedirect. com/science/article/pii/S0022024814008379

26 D. Vempaire, F. Fettar, L. Ortega, F. Pierre, S. Miraglia, A. Sulpice, J. Pelletier, E. K. Hlil, and D. Fruchart, Journal of Applied Physics 106, 073911 (2009), http://scitation.aip.org/content/aip/journal/ jap/106/7/10.1063/1.3238290

27 H. Nishihara, K. Suzuki, R. Umetsu, T. Kanomata, T. Kaneko, M. Zhou, M. Tsujikawa, M. Shirai, T. Sakon, T. Wada, K. Terashima, and S. Imada, Physica B: Condensed Matter 449, 85 (2014), ISSN 0921-4526, http://www.sciencedirect.com/science/article/pii/ S0921452614003998

28 C. Navío, J. Alvarez, M. J. Capitan, J. Camarero, and R. Miranda, Appl. Phys. Lett. 94, 263112 (2009)

29 C. Navío, M. J. Capitán, J. Álvarez, R. Miranda, and F. Yndurain, New J. Phys. 12, 073004 (2010)

${ }^{30}$ F. Faupel, W. Frank, M. P. Macht, H. Mehrer, K. Rätzke, H. Schober, S. K. Sharma, and H. Teichler, Rev. Mod. Phys. 75, 237 (2003)

31 H. Matzke, in Defect and Diffusion Forum, Vol. 83 (Trans Tech Publ, 1992) pp. 111-130

32 A. Tayal, M. Gupta, N. P. Lalla, A. Gupta, M. Horisberger, J. Stahn, K. Schlage, and H.-C. Wille, Phys. Rev. B 90, 144412 (Oct 2014), http://link.aps.org/doi/10.1103/ PhysRevB.90.144412

${ }^{33}$ H. Schmidt, G. Borchardt, M. Rudolphi, H. Baumann, and M. Bruns, Appl. Phys. Letters 85, 582 (2004)

${ }^{34}$ H. Schmidt, M. Gupta, and M. Bruns, Phys. Rev. Lett. 96, 055901 (2006)

35 A. D. L. Claire, British Journal of Applied Physics 14, 351 (1963), http://stacks.iop.org/0508-3443/14/i=6/ $\mathrm{a}=317$

${ }^{36}$ I. Kaur, Y. Mishin, and W. Gust, Fundamentals of Grain and Interphase Boundary Diffusion (Wiley, 1995) ISBN 9780471938194, http://books.google.co.in/books?id= RnmAQgAACAAJ

37 S. Basu, C. Nayak, A. K. Yadav, A. Agrawal, A. K. Poswal, D. Bhattacharyya, S. N. Jha, and N. K. Sahoo, Journal of Physics: Conference Series 493, 012032 (2014), http: //stacks. iop.org/1742-6596/493/i=1/a=012032

38 D. M. Phase, M. Gupta, S. Potdar, L. Behera, R. Sah, and A. Gupta, AIP Conference Proceedings 1591, 685 (2014), http://scitation.aip.org/content/ aip/proceeding/aipcp/10.1063/1.4872719

39 A. Guinier

40 B. E. Warren, X-ray Diffraction (Courier Corporation, 1969)

41 B. D. Cullity, Elements of X-ray Diffraction (AddisonWesley,MA, 1978)

42 R. Brand, Wissenschaftlich Elektronik GmbH, Starnberg(1995)

43 D. M. Borsa and D. O. Boerma, Hyp. Int. 151-152, 31 (2003)

44 G. Chen, N. Jaggi, J. Butt, E. Yeh, and L. Schwartz, Journal of physical chemistry $\mathbf{8 7}, 5326$ (1983)

$45 \mathrm{G}$. Bunker, Introduction to XAFS: a practical guide to Xray absorption fine structure spectroscopy (Cambridge University Press, 2010)

46 T. Yamamoto, X-Ray Spectrometry 37, 572 (2008), ISSN 1097-4539, http://dx.doi.org/10.1002/xrs.1103

47 A. Pantelouris, H. Modrow, M. Pantelouris, J. Hormes, and D. Reinen, Chemical Physics 300, 13 (2004), ISSN 0301-0104, http://www.sciencedirect.com/science/ article/pii/S0301010404000059

48 C. Mitterbauer, C. HAbert, G. Kothleitner, F. Hofer, P. Schattschneider, and H. Zandbergen, Solid State Communications 130, 209 (2004), ISSN 0038-1098, http://www.sciencedirect.com/science/article/pii/ S0038109804000936

49 J. Pfluger, J. Fink, G. Crecelius, K. Bohnen, and H. Winter, Solid State Communications 44, 489 (1982), ISSN 0038-1098, http://www.sciencedirect. com/science/article/pii/0038109882901302

50 M. P. Rosenblum, F. Spaepen, and D. Turnbull, Appl. Phys. Lett. 37, 184 (1980)

51 J. Speakman, P. Rose, J. Hunt, N. Cowlam, R. E. Somekh, and A. Greer, J. Magn. Magn. Mat. 156, 411 (1996)

52 M. Gupta, A. Gupta, J. Stahn, M. Horisberger, T. Gutberlet, and P. Allenspach, Phys. Rev. B 70, 184206 (2004)

53 L. G. Parratt, Phys. Rev. 95, 359 (1954)

54 C. Braun, Parratt32- The Reflectivity Tool (HMI Berlin, 1997-99)

55 M. Gupta, A. Gupta, S. Rajagopalan, and A. K. Tyagi, Phys. Rev. B 65, 214204 (2002)

56 Y. Mishin and C. Herzig, Materials Science and Engineering: A 260, 55 (1999), ISSN 0921-5093, http://www.sciencedirect.com/science/article/pii/ s0921509398009782

57 T. Suzuoka, Journal of the Physical Society of Japan 19, 839 (1964), http://dx.doi.org/10.1143/JPSJ.19.839, http: //dx.doi.org/10.1143/JPSJ 19.839

58 J. C. Fisher, Journal of Applied Physics 22, 74 (1951)

59 L. G. Harrison, Trans. Faraday Soc. 57, 1191 (1961), http: //dx.doi.org/10.1039/TF9615701191

60 Y. Mishin and C. Herzig, Nanostructured Materials 6, 859 (1995), ISSN 0965-9773, proceedings of the Second International Conference on Nanostructured Materials, http://www.sciencedirect.com/science/article/ pii/0965977395001956

61 C. Paduani, Solid State Communications 148, 297 (2008), ISSN 0038-1098, http://www.sciencedirect. com/science/article/pii/S0038109808005164

62 B. Eck, R. Dronskowski, M. Takahashi, and S. Kikkawa, J. Mater. Chem. 9, 1527 (1999), http://dx.doi.org/10. 1039/A809935I 